\title{
The Construction and Application of Digital Resources in Rural Primary School English Teaching and Learning
}

\author{
Junhong Tang, Xinfa Yuan \\ Foreign Language Department, Baoding University, Baoding, China \\ Email: jessytang99@163.com
}

How to cite this paper: Tang, J.H. and Yuan, X.F. (2018) The Construction and Application of Digital Resources in Rural Primary School English Teaching and Learning. Social Networking, 7, 89-96. https://doi.org/10.4236/sn.2018.72007

Received: March 15, 2018

Accepted: April 24, 2018

Published: April 27, 2018

Copyright ( 2018 by authors and Scientific Research Publishing Inc. This work is licensed under the Creative Commons Attribution International License (CC BY 4.0).

http://creativecommons.org/licenses/by/4.0/

\begin{abstract}
To arouse rural primary school students' English learning interest, broaden their horizon and promote their critical thinking, we construct a series of digital education resources which include not only language points of phonetics, vocabulary, language skills of English teaching and learning but western and Chinese cultures. The results show teachers and students' roles and discourse power changed by using the digital education resources in the process of rural primary school English teaching and learning.
\end{abstract}

\section{Keywords}

English Teaching and Learning in Rural Primary School, Digital Education Resources, Construction and Application

\section{Introduction}

Reference [1] clearly states teaching and learning quality in rural primary school is supposed to be improved by constructing and applying digital resources. It is also helpful to solve the digital education gap between urban area and rural area. Reference [2] also points out that good digital teaching and learning resources should come into the rural primary school classroom. Reference [3] also puts forward the idea that suitable development and active utilization of curriculum resources would guarantee the proficiency of English teaching and learning.

In rural area, primary school students have little chance to communicate with others in English and there are few opportunities for them to use English in their daily life. They know little about English culture and the nature of English language. What's more, they are not able to concentrate on what they are learning for a long time, especially on the things they are not interested in, so it becomes 
more important to construct digital resources in rural primary school English teaching and learning.

\section{Review of Literature}

\subsection{Infrastructures, Transitional Systems and Trainings about Digital Learning}

In 2010, Korea Education and Research Information Service put forward the implementation of the program for the popularization of computer classrooms in primary school, especially in rural primary schools [4]. The UK also put emphasis on developing "Digital Self-confidence System" since 2011 [5]. In 2017, American White House launched Connect ED Plan [6] which states clearly that the transition of American education to digital learning would be realized within five years. In 2016, Japan issued Education Informationization Acceleration Plan, which defined the information application ability of the next generation [7].

\subsection{Chinese Rapid Progress in Digital Education Resources}

Chinese digital education resources got a rapid progress in recent years. The quantity of digital resources is from few to lots of. The quality of digital resources is also from low to high, from one way output to mutual interaction [8]. Reference [9] puts forward that the Education Information System which covers both urban and rural schools should be set up till 2020. The idea of promoting the construction and sharing of high quality education resources and speeding up high quality education resources to rural areas are also put forward in The Development of "National Education Plan" in 13th Five-Year [10]. In 2012, the Ministry of Education of China launched "Modern Distance Education Project for Primary and Secondary Schools in Rural Areas". According to "A Special Supervision Report on the National Education Information Work in 2016”, there were 64,000 teaching spots till November, 2014 [11].

\subsection{Current Application of Digital Education Resources}

\subsubsection{Emphasis on the Integration of Teachers' Information Technology and Teaching Practice}

In March, 2017, New Zealand issued a reported on evaluation of school network equipment. It stated clearly that it was very important for teachers to apply the information technology to change the teaching practice. In Singapore, they care much about the construction of infrastructures and they also put emphasis on the coordination and cooperation between teacher training and teaching application [12]. In China, "Survey on the Application of Information Technology Teaching in Primary and Secondary Schools" organized by Ministry of Education has conducted in eight provinces including Hebei, Henan, Anhui, Jiangxi, Shanxi, Shanxi, Gansu and Sichuan, which promote the application of information technology in English teaching and learning in rural primary schools [11]. Up till 2017, more than 10,000,000 primary school teachers and junior middle 
school teachers, more than 100,000 headmasters of primary schools and junior middle schools and more than 200,000 vocational College teachers received information training [13].

\subsubsection{Emphasis on the Integration of Education Resources and Curriculums}

In Thailand, One Tablet Per. Child Plan has been carried out since 2011 which intends to improve the effective application of digital resources in English vocabulary teaching [14]. America, Korean, Singapore, etc. encourage teachers integrate digital resources with curriculums. In China, more than 15,000,000 English teachers of primary and junior middle schools take part in the activity, One Teacher, One High Quality Class; One Class, One Famous Teacher. There are more than 13,000,000 lessons on the website [13]. The application of digital education resources makes up for the lack of English curriculum resources in rural areas.

\subsubsection{Problems Faced by Rural Primary School English Teachers}

\section{1) Poor ability of applying information technology.}

Lots of rural primary school teachers have difficulty in using digital education resources because they lack knowledge of information technology [15]. Although some rural primary school teachers are using digital education resources, the usage is only on the low level and they are not able to find out the key points and the difficult points in the process of integration between the information technology and the curriculum. Many rural primary school teachers are not able to make full use of the digital education resources.

2) Confusion in searching and selecting digital education resources.

Because of the poor ability of applying information technology, the rural primary school teachers meet many difficulties in searching and selecting suitable digital resources before millions of digital resources. What's worse, some remote rural primary school teachers even don't know how and where to find out digital education resources [16].

3) Weak consciousness of using digital education resources.

In daily teaching and learning, lots of rural primary school teachers are reluctant to use digital resources partly because of their large amount of work [15]. The most fundamental problem is the poor information literacy of the English teachers in rural areas. It causes their poor ability in searching, selecting, making and applying digital education resources.

\section{Proposed Approaches}

\subsection{Constructing Simple and Practical Digital Education Resources}

In order to arouse students' interest, broaden their horizons, cultivate critical thinking of the rural primary school students, the digital education resources should be simple and practical. Micro-lectures of phonetic module are supposed 
to offer standard pronunciation for rural primary school English teachers and students and help them erase their local accents in English pronunciation. Vocabulary micro-lectures are expected to offer different games and methods of English vocabulary teaching and learning. Typical video text and theme analysis should focus on cultivating the rural primary school students' critical thinking. There is also a module of western and Chinese culture. It means to broaden rural primary school students' horizon and make them know more about the foreign cultures. There are many famous stories and universal text in primary school students' Chinese textbook. Students have been familiar with them in Chinese, so a module of English version of those famous stories and universal texts is helpful to guide the students appreciate and enjoy English culture and the nature of English.

The digital education resources should not only include language points of phonetics, vocabulary, language skills of English teaching and learning but include western and Chinese culture. It includes both modules that can be used in class and modules that help rural primary school teachers improve their teaching ability. There are also such modules as lesson planning, English teaching methods and typical class of teaching.

\subsection{Rules in Applying the Digital Education Resources}

Three groups of experts guide the rural primary school English teachers to use the digital education resources. The first group refers to university experts who are interested in primary school English teaching and have knowledge of theories and methods of primary school English teaching and learning. The second group refers to primary school English instructors whose daily work is to help primary school English teachers improve their teaching ability and organize various kinds of teaching contests, activities of open classes and model classes. The third group refers to excellent primary school teachers who are very familiar with the daily teaching. The three groups cooperate with each other to make their guidance to maximizing synergy.

\subsection{Short-Term Centralism Training}

The three groups of experts regularly organize the rural primary school English teachers get together to learn how to make full use of the digital education resources. The rural primary school teachers who attend the short-term centralism training are supposed to train their colleagues when they return back to their own primary school.

\subsection{Centralized Guidance}

The three groups of experts come into the rural areas and organize the rural primary school English teachers get together at one school. The rural primary school teachers speak out their difficulties and puzzles met in the process of using the digital education resources. The university experts, the primary school 
English instructors and the excellent primary school teachers cooperate with the local primary English teachers to discuss how to solve these problems and work out practical solutions.

\subsection{Decentralized Guidance}

The three groups come into the rural primary school to attend and observe their normal English classes. After classes, the experts share their ideas and suggestions on the classes they attended. Meanwhile, the teachers who have classes should also share their own experience and ideas.

\subsection{Setting up an Online Forum of English Teaching and Learning}

The members of the online forum include the university experts, primary school English instructors, excellent primary school teachers and rural primary school English teachers. Each member is supposed to share ideas, resources, difficulties and puzzles in this forum. Each member is also expected to discuss and offer responses and ideas actively in this online forum.

\section{Results and Discussion}

\subsection{Changes of the Roles of Teachers and Students by Using Digital Education Resources}

According to ecological principles, the units in the same niche will compete with each other and their adaptability will be improved [17]. Meanwhile, "Symbiotic Effect" shows that exchange between individuals and mutual influence will greatly promote the whole group.

For one thing, by using digital education resources, rural primary school English teachers are able to broaden students' horizon, create a vivid and interesting phenomenon to learn English and make full use of situational language teaching. For another thing, rural primary school English teachers can guide and promote the rural students think for themselves easily and more frequently with the help of digital education resources. In the process of thinking for themselves, students' competitive and cooperative consciousness can be cultivated and students' strong inspiration to learn English can be promoted. In the process of using digital education resources, the teachers' role will change from instructor to learning partner, from broadcaster to communicator, from supervisor to prompter and from actor to director. At the same time, the students' role will change from mechanical receiver to active thinker, from passive listener to active questioner, from passive learner to active learner and from audience to actor. The changes of the roles of teachers and students are illustrated in the following Figure 1.

\subsection{Changes of the Discourse Power of Teachers and Students by Using Digital Education Resources}

Discourse is a kind of behavior which is used to meet some communication purposes. Discourse is also the connection of semantics and pragmatics. It can 


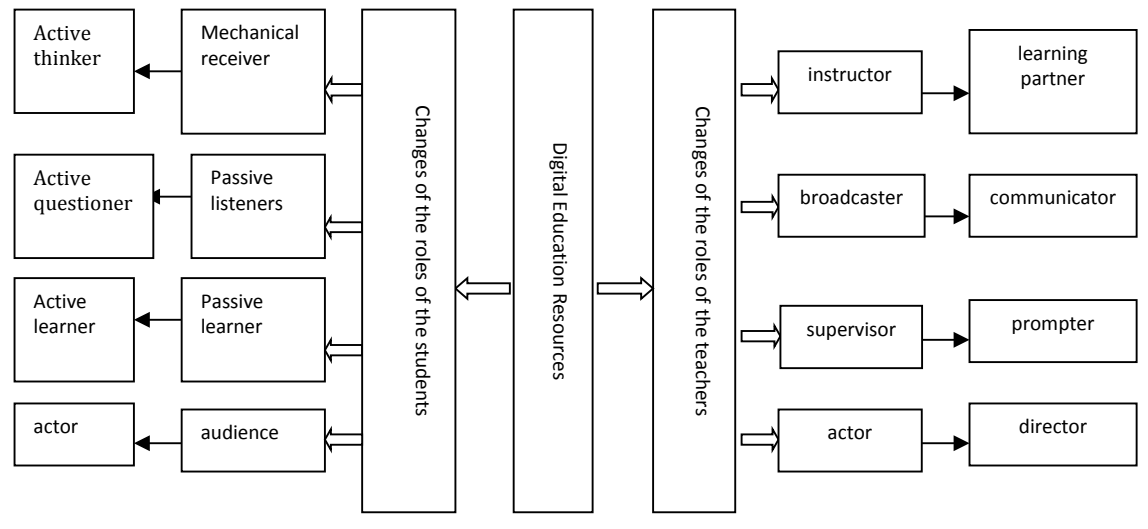

Figure 1. Changes of the roles of teachers and students.

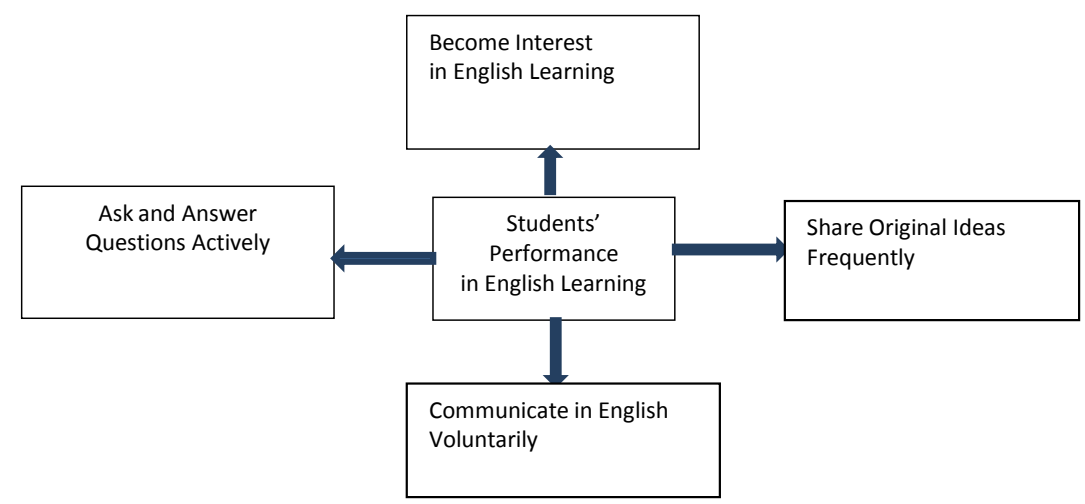

Figure 2. Changes of Students' Performance in English Learning.

be both in written form and oral form. It is a kind of thing that is under people's consciousness but it dominates the different languages, ideas, and behavior patterns of each person [18].

In the process of using digital education resources, the rural primary school students have much chance to express their ideas in English, get more opportunities to communicate with each other in English and become more interested and willing to learn English. It can be illustrated in Figure 2.

\section{Conclusions and Future Work}

In order to construct better and more practical rural primary school digital education resources, university experts, primary school English instructors and excellent primary English teachers are supposed to participate in the process of making, using and guiding. On the basis of deeply and fully understanding of Compulsory education English Curriculum Standard (2011 Edition), the three groups of experts should cooperate with each other, make full use of one's own advantages, try best to meet the maximum synergistic effects. The university experts, primary school English instructors and excellent primary English teachers should also regularly train the rural primary school teachers by means of centralized training, centralized guidance, decentralized guidance and online communication and discussion. In this way, rural primary school teachers will get more 
chances to communicate, discuss, share and learn from other primary school English teachers. Meanwhile, the university experts and primary school English instructors will get and collect more information and materials of the current situation in rural primary school English teaching and learning.

\section{Acknowledgements}

The paper is under the project of "Implementation Plans of Critical Teaching Strategies in Education and Training (20170801)". All the project members made their contributions to the paper. I also thank Only International Education. It made the investigation possible.

\section{References}

[1] Ministry of Education of the People's Republic of China. (2012) The Ten Year Development Plan in Education Information (2010-2020). http://www.edu.cn/zong_he_870/20120330/t20120330_760603.shtml

[2] Ministry of Education of the People's Republic of China. (2018) The Key Points in 2018 of the Teachers Work Department of Ministry of Education. http://www.moe.gov.cn/s78/A10/A10_gggs/A10_sjhj/201801/t20180124_325390.ht $\underline{\mathrm{ml}}$

[3] Ministry of Education of the People's Republic of China. (2012) Compulsory Education English Curriculum Standard (2011 Edition). Beijing Normal University Press, Beijing.

[4] Wikipedia. (2010) Education in South Korea. https://en.wikipedia.org/wiki/Education_in_South_Korea

[5] Wu, D., Yu, L.Q., Li, C.C. and Wei, X.R. (2017) Promoting Path and Enlightenments of Education Information Policy in Developed Country. E-Education Research, 5-13, 28.

[6] The White House Office of the Press Secretary. (2016) FACT SHEET: President Obama Announces Connect All Initiative.

https://obamawhitehouse.archives.gov/the-press-office/2016/03/09/fact-sheet-presi dent-obama-announces-connectall-initiative

[7] Zhang, W., Li, Z. and Aolintai, Y. (2017) The Analysis of Japan's Education Information Policy and Its Enlightenment to China. Modern Education Technology, 6-7.

[8] Du, Z.Y. (2011) Speech by Vice Minister Zhanyuan Du at the Symposium on the Construction and Sharing of Educational Resources. China Educational Technology, 1-3.

[9] Ministry of Education of the People's Republic of China. (2010) The National Long-Term Education Reform and Development Plan (2010-2020 Years). http://www.moe.edu.cn/srcsite/A01/s7048/201007/t20100729_171904.html

[10] Ministry of Education of the People's Republic of China. (2016) The Development of "National Education Plan" in 13th Five-Year. http://www.moe.edu.cn/srcsite/A16/s3342/201606/t20160622_269367.html

[11] Ministry of Education of the People's Republic of China. (2016) A Special Supervision Report on the National Education Information Work in 2016. http://www.myzaker.com/article/5818576c1bc8e04d6f000004

[12] Wikipedia. (2018) North Region, Singapore. https://en.wikipedia.org/wiki/North_Region,_Singapore 
[13] Vungthong, S., Djonov, E. and Torr, J. (2017) Images as a Resource for Supporting Vocabulary Learning: A Multimodal Analysis of Thai EFL Tablet Apps for Primary School Children. Tesol Quarterly, 32-58. https://doi.org/10.1002/tesq.274

[14] Du, Z.Y. (2017) Breakthrough Progress in Education Information in China. http://info.edu.hc360.com/2017/11/290933787090.shtml

[15] Duan, J.G. (2017) The Good Effects and Puzzles in the Project of Rural Teaching Spots Construction. New Curriculum, 112.

[16] Wang, J.S. (2017) The Construction and Application of Digital Education Resources. Education of Chinese Information and Technology, 11, 141-142.

[17] Liu, S. (2011) Classroom Ecology-Harmony and Creation. People's Education Press, Beijing.

[18] Hu, X.C. (2000) Literature Discourse and Power Discourse. Zhejiang People's Press, Hangzhou. 